\title{
A few attempts to increase the amount of a drug coated onto the microneedles
}

\section{Ling Liang}

Beijing University of Chemical Technology

\section{Yang Chen}

Beijing University of Chemical Technology

\section{Gui Yao Ren}

Beijing University of Chemical Technology

\section{Jun You Li}

Beijing University of Chemical Technology

\section{Xin Dong Guo ( $\nabla$ xdguo@buct.edu.cn )}

Beijing University of Chemical Technology https://orcid.org/0000-0001-5581-4253

\section{Research Article}

Keywords: microneedle, high drug loading, dipping, pharmacokinetic studies

Posted Date: March 31st, 2021

DOI: https://doi.org/10.21203/rs.3.rs-245374/v1

License: (c) (1) This work is licensed under a Creative Commons Attribution 4.0 International License. Read Full License 


\section{Abstract}

As an approach of painless administration, coated microneedles (MNs) have an increasing attention on the drug loading capacity to meet higher drug dosage requirement. In this work, the solid and coated MNs were successfully fabricated using hot-compaction process and dipping with a dam board reservoir. The maximum drug loading of different height, arrays and coating solutions reached $118 \mu \mathrm{g}$, which was hundreds of times the unmodified coated MNs. The in vitro drug delivery was also evaluated and the result revealed that the coated MNs fabricated could achieve about $90 \%$ drug delivery efficiency. The insulin-coaded MNs holding $0.5 \mathrm{IU}$ of insulin were fabricated with dipping method, which had the same therapeutic effect on diabetic mice compared with the injection of the same dose. All the results demonstrated that coated MNs could meet the dosage needs of diseases by improving the height, arrays and coating solutions.

\section{Introduction}

Coated MNs have been a promising and attractive medical tool for painlessly delivering a wide range of active drugs into the skin. In previous studies, different drugs, such as vaccine [1-4], desmopressin [5], human growth hormone [6], salmon calcitonin [7], lidocaine [8, 9] and DNA [10-13], are rapidly delivered into the skin using coated MNs due to the superior insertion ability. Moreover, the coating drugs on the MNs may prolong the long-term stability when the active drugs are stored in a solid state [3, 14-20]. A study demonstrates that the M2e5x VLP-coated MNs can maintain the M2e antigenicity and immunogenicity for 8 weeks at room temperature [21].

These advantages make coated MNs have the promising carrier to painlessly deliver drugs into the skin. However, the application and development of coated MNs are limited due to the uniformity and amount of drug loading. To fabricate coated MNs with homogeneous drug dose, several approaches have been proposed gradually. In the inkjet printing process, the drug loading is controlled by adjusting the size of droplets [15]. In another study on coated MNs, the drug loading is controlled by changing the height of these coating layers while dipping the coating solutions [16]. Unfortunately, another difficulty, low drug dose still puzzles people. Some people increased the drug loading of coated MNs by increasing the number of dipping $[22,23]$. A study on coated MNs showed that the drug dose of hemagglutinin antigen is only $140 \mathrm{ng}$ per needle even the concentration of hemagglutinin antigen is up to $25 \mathrm{mg} / \mathrm{mL}$ [3]. Moreover, the drug dose is only $10 \mathrm{ng}$ or about $100 \mathrm{ng}$ per needle in some studies [5, 24-26]. Obviously, low drug loading cannot reach dose requirements during the application.

To improve the drug loading of coated MNs, increasing the dipping times and coating height in the fabrication process are the main solutions. After dipping these coating solutions several times, the drug loading may be improved in different degrees. However, it is hard to fabricate coated MNs with homogeneous drug loading. In addition, the MN tips cannot penetrate the skin due to the cover of loaded thick coating layers. Nowadays, to improve the loaded drug dose, another approach is increasing coating height even covering the whole MN patch with the coating layer. However, in the skin penetration 
experiment, only a part of MN body can insert into the skin due to the elastic property of the skin. Only a part of drugs can be delivered to the subcutaneous tissue. As a result, the drug delivery efficiency is low. Moreover, precise control of drug delivery in the process is still a challenge. Therefore, fabricating coated MNs with high drug loading, homogeneous drug loading and high drug delivery efficiency puzzle people all the time.

To overcome these drawbacks and fabricate coated MNs with high drug loading, a dip-coating process is proposed. As described previously [27], plylactic acid (PLA) was chosen to fabricate the solid MNs using the hot-compaction process. Coating formulation was the key to increase the drug loading. First, several additives were dissolved in deionized (DI) water to prepare solutions. Afterwards, these formulations formed by uniformly mixing the solutions with drugs. In the dip-coating process, a $300 \mu \mathrm{m}$-tall dam board was adhered to the reservoir to unify the height of coating layers. By immersing PLA MNs with coating formulations, coated MNs with high drug loading were fabricated. The effects of coating formulations and $\mathrm{MN}$ height on drug loading on MN tips were studied detailedly. Coated MNs were inserted into the porcine cadaver skin to determine the ability to deliver numerous drugs. In vivo pharmacokinetic studies in mice were conducted to evaluate the feasibility that coated MNs were used to treat diabetes. The result showed that insulin-coated MN and subcutaneous injection have the same therapeutic effect on diabetic mice.

\section{Materials And Methods}

\subsection{Materials}

Polyvinyl alcohol (PVA, MW 6000) was obtained from ACROS Organics, Geel, Belgium. Polydimethylsiloxane (PDMS, Sylgard 184) was purchased from Dow Corning, Midland, MI). Other chemicals include sucrose (Sigma-Aldrich, St Louis, MO), sulforhodamine B (MW 559 Da, Sigma Aldrich) and polylactic acid particles (PLA, $1.0 \mathrm{dL} / \mathrm{g}$, Birmingham Polymer, Pelham, AL). Female BALB/c mice were obtained from the Institute of Laboratory Animal Sciences (ILAS). Two weeks before the experiment, the mice were made diabetics by injecting streptozotocin (STZ, Sigma-Aldrich, St Louis, Mo, USA, 50 $\mathrm{mg} / \mathrm{kg} \mathrm{BW}$ ). Insulin was purchased from Jiangsu Wanbang Pharm. Company (Xuzhou, China). Porcine cadaver skins purchased from a local slaughterhouse was utilized in vitro test.

\subsection{Fabrication of PLA MNs}

Using the method mentioned previously [28], solid MNs were fabricated from PLA particles using the hotcompaction process. First, PLA particles was placed on the PDMS mold and heated in vacuum drying oven (Biocool, Pilot1-2LD, China) for $40 \mathrm{~min}$ at $200^{\circ} \mathrm{C}$. Then, press the molten PLA and cool to room temperature. In order to prepare the desired solid MNs, the PDMS molds with different hole heights (550 $\mu \mathrm{m}, 650 \mu \mathrm{m}$ and $750 \mu \mathrm{m})$ and hole arrays $(5 \times 5,8 \times 8,10 \times 10,11 \times 11,15 \times 15)$ were fabricated. Finally, solid MNs with heights of $550 \mu \mathrm{m}, 650 \mu \mathrm{m}$ and $750 \mu \mathrm{m}$ and arrays of $5 \times 5,8 \times 8,10 \times 10,11 \times 11,15 \times$ 15 were fabricated. 


\subsection{Coating formulations}

In order to assure the drug loading, the drug was mixed with the coating solution in different ratio. The coating solution was composed of $7.7 \%$ PVA $(w / w), 15.4 \%$ sucrose $(w / w)$ and $76.9 \%$ deionized $(\mathrm{DI})$ water $(\mathrm{w} / \mathrm{w})$. Sulforhodamine B was selected as a model drug. The weight ratio of coating solution to model drug was 2:0.5, 2:0.75, 2:1 and 2:1.25, respectively (formulation listed in Table 1).

Table.1. Coating formulations for the preparation of coated polymer MNs.

\begin{tabular}{|lllll|}
\hline Formulation ID & I & II & III & IV \\
\hline Solution-solid ratio $(\mathrm{w} / \mathrm{w})$ & $2: 0.5$ & $2: 0.75$ & $2: 1$ & $2: 1.25$ \\
\hline
\end{tabular}

The solution contained 7.7 \% PVA, $15.4 \%$ sucrose and $76.9 \%$ DI water (wt,\%). The solid was sulforhodamine B.

\subsection{Fabrication of coated MNs}

To fabricate coated MNs with high drug loading, a dip-coating device was used as mentioned before [29]. First, the reservoir was filled with the coating solution until the liquid level was tangent to the top of the reservoir. Then, the $300 \mu \mathrm{m}$-tall dam board was adhered to the top of the reservoir (simply described as dam board reservoir) so that the coating layer was $300 \mu \mathrm{m}$ away from the base of the MN. The portable holder was moved down until the MN patch touching the dam board, maintaining for $10 \mathrm{~s}$, as shown in Figure 1A. Finally, the fabricated coated MNs were dried in vacuum drying oven at $25^{\circ} \mathrm{C}$ for $12 \mathrm{~h}$ for later use. All microneedle images were taken by the stereomicroscope (SZX7, Olympus, Japan).

\subsection{In vitro skin insertion test}

To determine the application effect of coated MNs with high drug loadings, the MN patch was used to manually insert the porcine cadaver skin. Before the insertion test, the hair on the skin surface was removed using a stainless razor. Afterwards, the skin was sprayed with $75 \%$ ethanol to wipe off the dirt on the surface. The dried coated MNs were manually inserted into the porcine cadaver skin and left for 2 min. After withdrawal, the used coated MN patch and skin were pictured using a stereomicroscope (SZX7, Olympus, Japan). To observe the depth of drug in the skin tissue, the skin was sliced and pictured.

\subsection{Measurement of drug loading and drug delivery efficiency}

To fabricate coated MNs with high and homogeneous drug loading, the different formulations of coating solution were coated. The amount of sulforhodamine B coated on the PLA MNs $(n=10)$ was determined by a microplate reader (Fluoroskan Ascent ${ }^{\circledR}$, Thermo Scientific, China). Briefly, sulforhodamine B coated on the MNs was dissolved in DI water. Then, $100 \mu \mathrm{l}$ of the extracted solution and standard solution were injected into the 96 -well plate. We could calculate out the drug loading of sulforhodamine $B$ by measuring the fluorescence intensity according to a calibration curve constructed from different concentrations 
sulforhodamine B solutions. In a same method, the residual amount of sulforhodamine B was measured by dissolving coated MNs removed after inserting the skin for $2 \mathrm{~min}$ in DI water. The mass of sulforhodamine B left behind on the skin surface was estimated by applying tape (Scotch super 33, McMaster-Carr). Dissolve the material removed by the tape in deionized water, and calculate the residual amount of drug on the skin surface according to the fluorescence intensity. The calculation result showed that there was almost no residual amount, so this part was ignored. Finally, the drug delivery efficiency was calculated by dividing the amount delivered into the skin by the amount of non-inserted MNs.

\subsection{In vivo transdermal delivery via insulin-coated MNs}

A mouse model (BALB/c female mice, 16 18 g) of type 1 diabetes was created as mentioned in prior experiment [28]. First, dry STZ powder was dissolved in sodium citrate buffer $(\mathrm{pH} 4.5)$ and the concentration was $10 \mathrm{mg} / \mathrm{mL}$. Afterwards, healthy mice were injected STZ with a dose of $200 \mathrm{mg} / \mathrm{Kg}$ by intraperitoneal injection. Before injection of STZ, mice were fasted overnight but could receive water. Finally, after $72 \mathrm{~h}$, the diabetic mice models were successfully created when the blood glucose (BG) level reached to 300-550 mg/dL monitored with a One Touch glucometer (LifeScan, Inc., Milpitas, CA, USA).

To test the transdermal delivery ability of coated MNs with high drug loading, insulin-coated MNs were fabricated. The coated solution and fabrication method were the same as the section 2.3 and 2.4 except that the model drug was replaced by insulin. The solution and insulin were mixed in a ratio of $3 / 1$ by weight, so that each coated MN patch had $0.5 \mathrm{IU}$ insulin. For comparison, $50 \mu \mathrm{L}$ of solution containing $0.5 \mathrm{IU}$ insulin was injected in the injection group. Before $\mathrm{MN}$ administration, the back of the mice was shaved. And coated MNs with $0.5 \mathrm{IU}$ insulin were inserted into the back skin of mice to test the treatment effect.

To continuously determine the blood glucose level, $5 \mu \mathrm{L}$ of blood samples were tested at different time intervals after delivering insulin to mice. The blood glucose level was tested at $0 \mathrm{~h}, 0.5 \mathrm{~h}, 1 \mathrm{~h}, 1.5 \mathrm{~h}, 2 \mathrm{~h}$, $2.5 \mathrm{~h}, 3 \mathrm{~h}, 3.5 \mathrm{~h}, 4 \mathrm{~h}, 5 \mathrm{~h}, 5.5 \mathrm{~h}, 6 \mathrm{~h}, 7 \mathrm{~h}$ and $8 \mathrm{~h}$ after delivering insulin. During blood glucose monitoring, the mice were fasted and deprived water.

\section{Results And Discussion}

\subsection{Fabrication of coated MNs with high drug loading}

Polylactic acid (PLA) was elected as the solid MN materials because of its biocompatibility and biodegradability. The different heights and arrays solid MNs were fabricated by changing the size of the PDMS mold with the hot-compaction process. In this process, the solid MNs with the height of $550 \mu \mathrm{m}$, $650 \mu \mathrm{m}$ and $750 \mu \mathrm{m}$ were prepared. The main factor that restricts the drug loading was the drug content in coating solution and the size of the MNs. In this study, the coating solution was prepared by changing the ratio of the model drug to the liquid to increase the drug content. Figure 1B1 and 1B2 are partial enlarged images of solid $\mathrm{MN}$ and coated $\mathrm{MN}$, respectively, to observe the shape of $\mathrm{MN}$ more clearly. Figure 1C1-1C3 showed coated MNs with the coating formulation $\nabla$ and height of 550, 650 and $750 \mu \mathrm{m}$. 


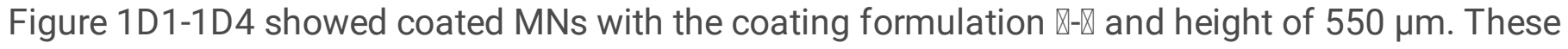
images indicated that the coating method of Figure $1 \mathrm{~A}$ can be used to uniformly coat different concentrations of coating solutions on MNs of different heights.

\subsection{In vitro insertion capability}

In Chen's works [29], the solid polymer microneedles used are the same as this study. The mechanical property of solid MN and coated MN were measured by a dynamometer. The mechanical properties curves of both MNs almost coincide, indicating that the coating will not affect the mechanical properties of the MNs and the MNs have sufficient mechanical properties. The solid MN was pierced into 8 layers of parafilm (each layer has a thickness of $127 \mu \mathrm{m}$ ). The MN could pierce through 4 layers of parafilm, and the fifth layer of parafilm could see obvious indentations, but there were no pierced holes. The result indicated that the $\mathrm{MN}$ has enough mechanical properties to penetrate the parafilm with a thickness of $508 \mu \mathrm{m}$. Images of the pierced parafilm were not collected at the time.

It is important to prepare coating formulations that not only adhere to MNs, but adhere to them during bypass the stratum corneum and insertion into the skin. However, in order to increase the drug loading, the amount of thickener was decreased, which leads to the decrease of the adhesion between the coating solution and $\mathrm{MN}$. It may cause the coating to fall off when the coated MN inserted into the skin, making the drug delivery efficiency reduce.

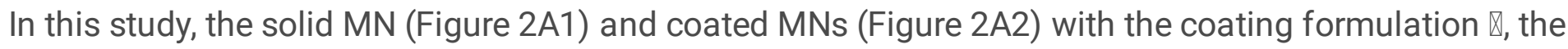
height of $650 \mu \mathrm{m}$ and the array of $5 \times 5$ were prepared. To determine the insertion capability and the transdermal drug delivery in vitro, the coated $\mathrm{MN}$ was inserted into porcine cadaver skin for $2 \mathrm{~min}$. After inserting and removing, surface examination of the treated skin showed an array of red dots corresponding to sites of MN insertion and coating deposition from the array (Figure 2B1 and 2B2). These red dots that remained on the skin indicated the successful penetration of MNs into skin. Almost no residue was observed on the solid $\mathrm{MN}$, as shown in Figure 2A2, indicating delivery of the drugs into skin. In Figure $2 \mathrm{C} 1$ and $2 \mathrm{C} 2$, the distance $(350 \mu \mathrm{m})$ of the parallel dotted lines indicated the depth of the MN insertion, indicating that all the drugs on the MNs were delivered into the skin without falling off. Taken together, consequently, the coated MN arrays with high drug loading showed excellent performance in vitro skin insertion, which suggested these MNs were an effective means of transdermal delivery of drugs.

\subsection{Determination of drug loadings and drug delivery efficiency}

In order to prepare coated microneedles with high drug loading and high drug-loading efficiency, the two crucial parameters of drug loading and drug delivery efficiency were evaluated. In this study, different heights $(550 \mu \mathrm{m}, 650 \mu \mathrm{m}, 750 \mu \mathrm{m})$ PLA MNs were successfully fabricated with hot-compaction process by changing the cavity depth of the PDMS mold. The coating formulation $\nabla$ were chosen to fabricate the different heights $(550 \mu \mathrm{m}, 650 \mu \mathrm{m}, 750 \mu \mathrm{m})$ coated microneedles corresponding to coating layer heights of $250 \mu \mathrm{m}, 350 \mu \mathrm{m}, 450 \mu \mathrm{m}$ by using the $300 \mu \mathrm{m}$ dam board, as shown in Figure 3B. Chen et al. [29] also 
fabricated sulforhodamine-coated MNs with heights of $550 \mu \mathrm{m}, 650 \mu \mathrm{m}$, and $750 \mu \mathrm{m}$, and their drug loadings of single MN were $12 \mathrm{ng}, 14 \mathrm{ng}$, and $18 \mathrm{ng}$, respectively. As shown in Figure 3A, the amount of drug loadings of single MN was $450 \mathrm{ng}, 570 \mathrm{ng}$ and $750 \mathrm{ng}$, respectively, which is about 40 times the drug loading of the coated MNs prepared by Chen [29]. Compared with the increase of height of the coated microneedle, the amount of the drug loading does not increase proportionally, which is related to the higher the height of the microneedle and the smaller the diameter of the upper side. The drug delivery efficiency of different height microneedles was approximately $90 \%$, which was as same as that of Chen's preparation of MNs, indicating that it has no great relationship with the height and drug loadings of the MNs.

In addition, the coating formulation was a vital factor during the fabrication of the high drug loading coated microneedles. In this part, the height of $650 \mu \mathrm{m}$ of the solid microneedle were chosen. As shown in

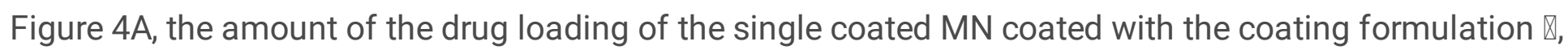
$\bigotimes, \bigotimes, \bigotimes$ were $260 \mathrm{ng}, 470 \mathrm{ng}, 570 \mathrm{ng}$ and $770 \mathrm{ng}$, respectively. As the concentration of the drug in coating formulation increased, the amount of drug loading increased. However, the viscosity of the coating solution decreased with the increase of the drug loading, resulting in a decreased adhesion of the coating solution on the MNs and a decreased drug delivery efficiency, which could attribute to a decrease in PVA and sucrose content in percentage, as shown in Figure 4A. Figure 4B showed coated MNs coated with coating formulations $\mathbb{\bigotimes}-\mathbb{\Xi}$. It can be clearly seen that as the concentration of the coating solution increases, the thicker the coating layer.

\subsection{Large-scale fabrication of MNs with high drug loadings}

In order to further increase the drug loading, another measure we took was to change the array of the

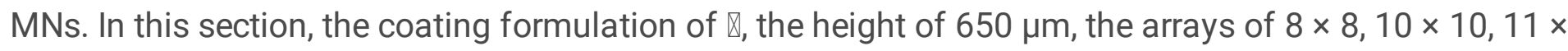
11 and $15 \times 15$ were chosen. The coated MNs with high drug loadings were fabricated with dipping method, as shown in Figure 5A-D. The drug was uniformly distributed in the upper part of the MNs, indicating that the increase of the $\mathrm{MN}$ array will not affect the distribution of the coating solution. Figure $5 \mathrm{E}$ showed the drug loading of the whole MN patch with different arrays. The drug loading of each $\mathrm{MN}$ patch is $36 \mu \mathrm{g}, 45 \mu \mathrm{g}, 56 \mu \mathrm{g}$, and $118 \mu \mathrm{g}$, corresponding with arrays of $8 \times 8,10 \times 10,11 \times 11$, and $15 \times$ 15. Serpe et al. [30] fabricated sulforhodamine-coated MNs with a height of $700 \mu \mathrm{m}$, drug loading of 15 $\mu \mathrm{g}$ and 57 needles, and drug loading of single needle was $263 \mathrm{ng}$. The drug loading of single needle with an array of $8 \times 8$ is $562.5 \mathrm{ng}$, which is more than twice that of Serpe [30]. Although the MN array reached $15 \times 15$, the area of the MN patch was only $1 \mathrm{~cm}^{2}$, indicating that the MN array can be appropriately increased to increase the drug loading, thereby achieving the purpose of treatment. For example, for the treatment of some skin diseases such as psoriasis, under the premise of increasing the drug loading, the $\mathrm{MN}$ array can be appropriately increased to increase the treatment area [31].

3.5 In vivo pharmacokinetic studies in mice 
To evaluate the effect of coated MNs in the treatment of diabetic mice, the insulin-loated MNs were prepared. First, the solution containing $14.3 \%$ PVA, $14.3 \%$ sucrose and $71.4 \%$ DI water (wt.\%) was prepared. Then, the insulin coating solution were prepared by mixing the insulin to the solution. The insulin-coaded MNs holding $0.5 \mathrm{IU}$ of insulin were fabricated with dipping method. To deteimine the in vivo efficacy of the prepared insulin-coaded MNs, the insulin was delivered into the body of the diabetic mouse in the way of subcutaneous injection and insulin-coaded MN. The insulin-coated MN were vertically and manually inserted into the skin for about $10 \mathrm{~s}$ and remained on the skin for $2 \mathrm{~min}$.

Figure $6 \mathrm{~A}$ showed the mouse back skin situation before and after $\mathrm{MN}$ administration. And the mice back skin has recovered after the insertion of insulin-coated $M N$ for $1 \mathrm{~h}$, indicating that the coated $\mathrm{MN}$ can provide a safe method for transdermal drug delivery. There are 25 clear pores on the mice skin, indicating that the insulin-coaded coated MN successfully inserted into the skin. There were almost no residue on the $\mathrm{MN}$ after removal, indicating that the insulin were almost transferred into the skin (Figure 6B). Figure $6 \mathrm{C}$ showed the effect of blood glucose level after a subcutaneous injection and an administration of insulin-coated MN array. The "initial" is the blood glucose value detected at $0 \mathrm{~h}$ in Figure $6 \mathrm{C}$ at the beginning of the in vivo experiment. The ratio of the monitored blood glucose is the ratio of the monitored blood glucose to the initial value. The untreated mice remained hyperglycemic for eight hours. The blood glucose in mice treated with subcutaneous injection of $0.5 \mathrm{IU}$ insulin quickly delined within $0.5 \mathrm{~h}$ and reached the stable value (15\%) at $1.5 \mathrm{~h}$ for $3.5 \mathrm{~h}$, returned to the initial value at $8 \mathrm{~h}$, a similar blood glucose level profile was observed in mouse treated with the same dose of insulin-coated MN arrays, confirming that the proposed MNs displayed a similar effect to subcutaneous injection on hypoglycemic administration. In a word, the use of the insulin-coated $\mathrm{MN}$ arrays for treatment of diabete provided useful information for future in vivo animal studies.

\section{Conclusion}

In summary, the different heights (550, 650 and $750 \mu \mathrm{m})$ and arrays $(5 \times 5,8 \times 8,10 \times 10,11 \times 11$ and 15 $\times 15)$ solid MNs and coated MNs were successfully fabricated with hot-compaction and dipping method, respectively. Then the in vitro insertion capability, drug loading, drug delivery efficiency and in vivo pharmacokinetic studies were investigated. After inserting into the skin with coated $\mathrm{MN}$, clear red spots were left on the skin and the insertion depth was $350 \mu \mathrm{m}$, indicating that the coated MN had sufficient mechanical properties to insert into the skin and deliver drugs into the skin. Coated MNs with a height of $550,650,750 \mu \mathrm{m}$ and array of $8 \times 8,10 \times 10,11 \times 11$, and $15 \times 15$ had drug loading of $450 \mathrm{ng}, 570 \mathrm{ng}$,

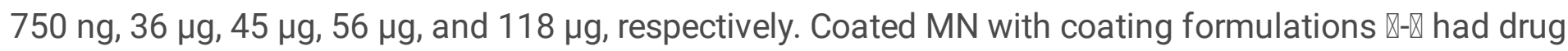
loadings of $260 \mathrm{ng}, 470 \mathrm{ng}, 570 \mathrm{ng}$ and $770 \mathrm{ng}$, respectively. The drug delivery efficiency of coated MNs reached $90 \%$ expect that the coated MNs with coating formulation $\otimes$ had only $80 \%$, due to the week adhesion between the coating solution and the MNs. Insulin-coated MNs have the same therapeutic effect on diabetic mice compared with the injection of the same dose. To sum up, we could change the height, arrays and the concentration of coating solutions to increase drug loading of coated MNs to meet treatment needs and the coated MNs have potential to serve as a noninvasive and painless method to treat some diseases. 


\section{Declarations}

\section{Acknowledgments}

This work was financially supported by the National Natural Science Foundation of China (51873015), the Joint Project of BRC-BC (Biomedical Translational Engineering Research Center of BUCT-CJFH) (XK2020-05) and the long-term subsidy mechanism from the Ministry of Finance and the Ministry of Education of PRC.

\section{Authors' contributions}

Ling Liang: Writing- Original draft preparation. Yang Chen: Methodology. Gui Yao Ren: Data curation. Jun You Li: Data Curation. Xin Dong Guo: Conceptualization, Project administration.

\section{Declaration of Informed Consent or Animal Studies}

All procedures of animal studies were conducted in accordance with the guidelines of China-Japan Friendship Hospital for care and use of laboratory.

\section{Consent for publication}

Written informed consent for publication was obtained from all participants.

\section{Availability of data and materials}

All data generated or analysed during this study are included in this published article.

\section{Competing interests}

The authors declare that they have no conflict of interest.

\section{Funding}

This work was financially supported by the National Natural Science Foundation of China (51873015), the Joint Project of BRC-BC (Biomedical Translational Engineering Research Center of BUCT-CJFH) (XK2020-05).

\section{Acknowledgements}

The long-term subsidy mechanism from the Ministry of Finance and the Ministry of Education of PRC.

\section{References}

[1] Y.C. Kim, F.S. Quan, D.G. Yoo, R.W. Compans, S.M. Kang, M.R. Prausnitz, Enhanced memory responses to seasonal H1N1 influenza vaccination of the skin with the use of vaccine-coated 
microneedles, J. Infect. Dis. 201 (2010) 190-198. http://doi.org/10.1086/649228.

[2] Q. Zhu, V.G. Zarnitsyn, L. Ye, Z. Wen, Y. Gao, L. Pan, I. Skountzou, H.S. Gill, M.R. Prausnitz, C. Yang, R.W. Compans, Immunization by vaccine-coated microneedle arrays protects against lethal influenza virus challenge, Proc. Natl. Acad. Sci. 106 (2009) 7968-7973. http://doi.org/10.1073/pnas.0812652106.

[3] S. Kommareddy, B.C. Baudner, A. Bonificio, S. Gallorini, G. Palladino, A.S. Determan, D.M. Dohmeier, K.D. Kroells, J.R. Sternjohn, M. Singh, P.R. Dormitzer, K.J. Hansen, D.T. O'Hagan, Influenza subunit vaccine coated microneedle patches elicit comparable immune responses to intramuscular injection in guinea pigs, Vaccine 31 (2013) 3435-3441. http://doi.org/10.1016/j.vaccine.2013.01.050.

[4] A. Vrdoljak, M.G. McGrath, J.B. Carey, S.J. Draper, A.V. Hill, C. O'Mahony, A.M. Crean, A.C. Moore, Coated microneedle arrays for transcutaneous delivery of live virus vaccines, J. Control. Release 159 (2012) 34-42. http://doi.org/10.1016/j.jconrel.2011.12.026.

[5] M. Cormier, B. Johnson, M. Ameri, K. Nyam, L. Libiran, D.D. Zhang, P. Daddona, Transdermal delivery of desmopressin using a coated microneedle array patch system, J. Control. Release 97 (2004) 503-511. http://doi.org/10.1016/j.jconrel.2004.04.003.

[6] M. Ameri, M. Kadkhodayan, J. Nguyen, J.A. Bravo, R. Su, K. Chan, A. Samiee, P.E. Daddona, Human Growth Hormone Delivery with a Microneedle Transdermal System: Preclinical Formulation, Stability, Delivery and PK of Therapeutically Relevant Doses, Pharmaceutics 6 (2014) 220-234. http://doi.org/10.3390/pharmaceutics6020220.

[7] C. Tas, S. Mansoor, H. Kalluri, V.G. Zarnitsyn, S.-O. Choi, A.K. Banga, M.R. Prausnitz, Delivery of salmon calcitonin using a microneedle patch, Int. J. Pharm. 423 (2012) 257-263. http://doi.org/10.1016/j.ijpharm.2011.11.046.

[8] Y. Zhang, K. Siebenaler, K. Brown, D. Dohmeier, K. Hansen, Adjuvants to prolong the local anesthetic effects of coated microneedle products, Int. J. Pharm. 439 (2012) 187-192. http://doi.org/10.1016/j.ijpharm.2012.09.041.

[9] Y. Zhang, K. Brown, K. Siebenaler, A. Determan, D. Dohmeier, K. Hansen, Development of lidocainecoated microneedle product for rapid, safe, and prolonged local analgesic action, Pharm. Res. 29 (2012) 170-177. http://doi.org/10.1007/s11095-011-0524-4.

[10] H. Nam, H. Kim, Y. Park, J.H. Sung, B. Kim, H.C. Kim, J.W. Jang, J.B. Lee, Fabrication of DNA-coated microneedles for transdermal DNA delivery, Sci. Adv. Mater. 6 (2014) 2536-2539. http://doi.org/10.1166/sam.2014.2235.

[11] M. Pearton, V. Saller, S.A. Coulman, C. Gateley, A.V. Anstey, V. Zarnitsyn, J.C. Birchall, Microneedle delivery of plasmid DNA to living human skin: Formulation coating, skin insertion and gene expression, J. Control. Release 160 (2012) 561-569. http://doi.org/10.1016/j.jconrel.2012.04.005. 
[12] P.C. DeMuth, P.T. Hammond, D.J. Irvine, Transcutaneous delivery of plasmid DNA and degradable polymer nanoparticles from multilayer-coated microneedle arrays, Abstr. Pap. Am. Chem. Soc. 240 (2010).

[13] Y.C. Kim, J.M. Song, A.S. Lipatov, S.O. Choi, J.W. Lee, R.O. Donis, R.W. Compans, S.M. Kang, M.R. Prausnitz, Increased immunogenicity of avian influenza DNA vaccine delivered to the skin using a microneedle patch, Eur. J. Pharm. Biopharm. 81 (2012) 239-247.

http://doi.org/10.1016/j.ejpb.2012.03.010.

[14] M. Witting, K. Obst, M. Pietzsch, W. Friess, S. Hedtrich, Feasibility study for intraepidermal delivery of proteins using a solid microneedle array, Int. J. Pharm. 486 (2015) 52-58. http://doi.org/10.1016/j.ijpharm.2015.03.046.

[15] M.J. Uddin, N. Scoutaris, P. Klepetsanis, B. Chowdhry, M.R. Prausnitz, D. Douroumis, Inkjet printing of transdermal microneedles for the delivery of anticancer agents, Int. J. Pharm. 494 (2015) 593-602. http://doi.org/10.1016/j.ijpharm.2015.01.038.

[16] H.S. Gill, M.R. Prausnitz, Coated microneedles for transdermal delivery, J. Control. Release 117 (2007) 227-237. http://doi.org/10.1016/j.jconrel.2006.10.017.

[17] H.J. Choi, D.G. Yoo, B.J. Bondy, F.S. Quan, R.W. Compans, S.M. Kang, M.R. Prausnitz, Stability of influenza vaccine coated onto microneedles, Biomaterials 33 (2012) 3756-3769. http://doi.org/10.1016/j.biomaterials.2012.01.054.

[18] H. Li, Y. Low, H. Chong, M. Zin, C.-Y. Lee, B. Li, M. Leolukman, L. Kang, Microneedle-Mediated Delivery of Copper Peptide Through Skin, Pharm. Res. 32 (2015) 2678-2689. http://doi.org/10.1007/s11095-0151652-z.

[19] E.E. Peters, M. Ameri, X. Wang, Y.-F. Maa, P.E. Daddona, Erythropoietin-coated ZP-microneedle transdermal system: preclinical formulation, stability, and delivery, Pharm. Res. 29 (2012) 1618-1626. http://doi.org/10.1007/s11095-012-0674-z.

[20] Y. Ma, H.S. Gill, Coating solid dispersions on microneedles via a molten dip-coating method: development and in vitro evaluation for transdermal delivery of a water-insoluble drug, J. Pharm. Sci. 103 (2014) 3621-3630. http://doi.org/10.1002/jps.24159.

[21] M.-C. Kim, J.W. Lee, H.-J. Choi, Y.-N. Lee, H.S. Hwang, J. Lee, C. Kim, J.S. Lee, C. Montemagno, M.R. Prausnitz, S.-M. Kang, Microneedle patch delivery to the skin of virus-like particles containing heterologous M2e extracellular domains of influenza virus induces broad heterosubtypic cross-protection, J. Control. Release 210 (2015) 208-216. http://doi.org/10.1016/j.jconrel.2015.05.278.

[22] S.H. Baek, J.H. Shin, Y.C. Kim, Drug-coated microneedles for rapid and painless local anesthesia, Biomed. Microdevices 19 (2017) 1-11. http://doi.org/10.1007/s10544-016-0144-1. 
[23] Y.-C. Kim, F.-S. Quan, D.-G. Yoo, R.W. Compans, S.-M. Kang, M.R. Prausnitz, Improved influenza vaccination in the skin using vaccine coated microneedles, Vaccine 27 (2009) 6932-6938. http://doi.org/10.1016/j.vaccine.2009.08.108.

[24] G. Widera, J. Johnson, L. Kim, L. Libiran, K. Nyam, P.E. Daddona, M. Cormier, Effect of delivery parameters on immunization to ovalbumin following intracutaneous administration by a coated microneedle array patch system, Vaccine 24 (2006) 1653-1664.

http://doi.org/10.1016/j.vaccine.2005.09.049.

[25] K.J. Lee, S.H. Park, J.Y. Lee, H.C. Joo, E.H. Jang, Y.N. Youn, W. Ryu, Perivascular biodegradable microneedle cuff for reduction of neointima formation after vascular injury, J. Control. Release 192 (2014) 174-181. http://doi.org/10.1016/j.jconrel.2014.07.007.

[26] J.-M. Song, Y.-C. Kim, A.S. Lipatov, M. Pearton, C.T. Davis, D.-G. Yoo, K.-M. Park, L.-M. Chen, F.-S. Quan, J.C. Birchall, R.O. Donis, M.R. Prausnitz, R.W. Compans, S.-M. Kang, Microneedle delivery of H5N1 influenza virus-like particles to the skin induces long-lasting B- and T-cell responses in mice, Clin. Vaccine Immunol. 17 (2010) 1381-1389. http://doi.org/10.1128/cvi.00100-10.

[27] D.D. Zhu, Q.L. Wang, X.B. Liu, X.D. Guo, Rapidly separating microneedles for transdermal drug delivery, Acta Biomater. 41 (2016) 312-319. http://doi.org/10.1016/j.actbio.2016.06.005.

[28] D.P. Yin, J. Tao, D.D. Lee, J.K. Shen, M. Hara, J. Lopez, A. Kuznetsov, L.H. Philipson, A.S. Chong, Recovery of islet beta-cell function in streptozotocin-induced diabetic mice - An indirect role for the spleen, Diabetes 55 (2006) 3256-3263. http://doi.org/10.2337/db05-1275.

[29] Y. Chen, B.Z. Chen, Q.L. Wang, X. Jin, X.D. Guo, Fabrication of coated polymer microneedles for transdermal drug delivery, J. Control. Release 265 (2017) 14-21.

http://doi.org/10.1016/j.jconrel.2017.03.383.

[30] L. Serpe, A. Jain, C.G. de Macedo, M.C. Volpato, F.C. Groppo, H.S. Gill, M. Franz-Montan, Influence of salivary washout on drug delivery to the oral cavity using coated microneedles: An in vitro evaluation, Eur. J. Pharm. Sci. 93 (2016) 215-223. http://doi.org/10.1016/j.ejps.2016.08.023.

[31] X. Zhang, F. Wang, Y. Yu, G. Chen, L. Shang, L. Sun, Y. Zhao, Bio-inspired clamping microneedle arrays from flexible ferrofluid-configured moldings, Sci. Bull. 64 (2019) 1110-1117. http://doi.org/10.1016/j.scib.2019.06.016.

\section{Figures}


A

dip-coating
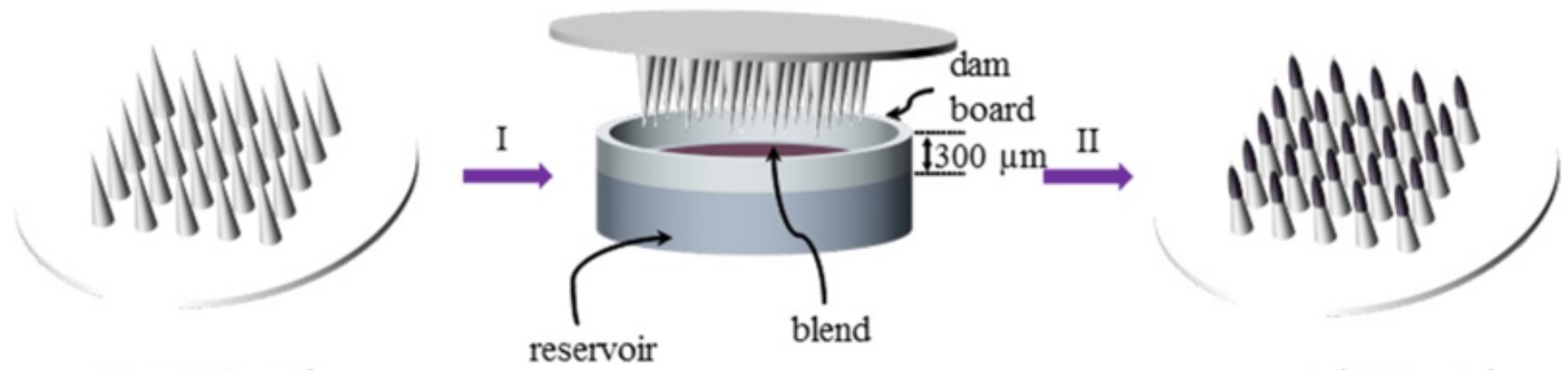

PLA MN patch

reservoir
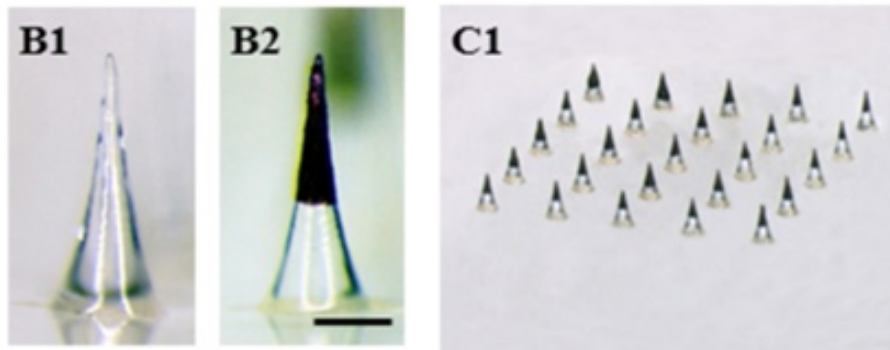

C2

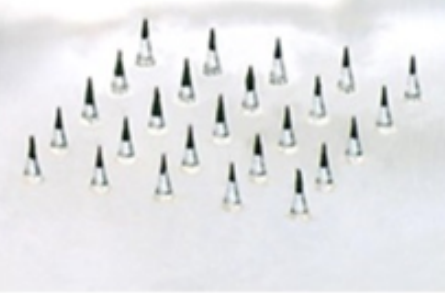

C3

coated $\mathrm{MN}$ patch
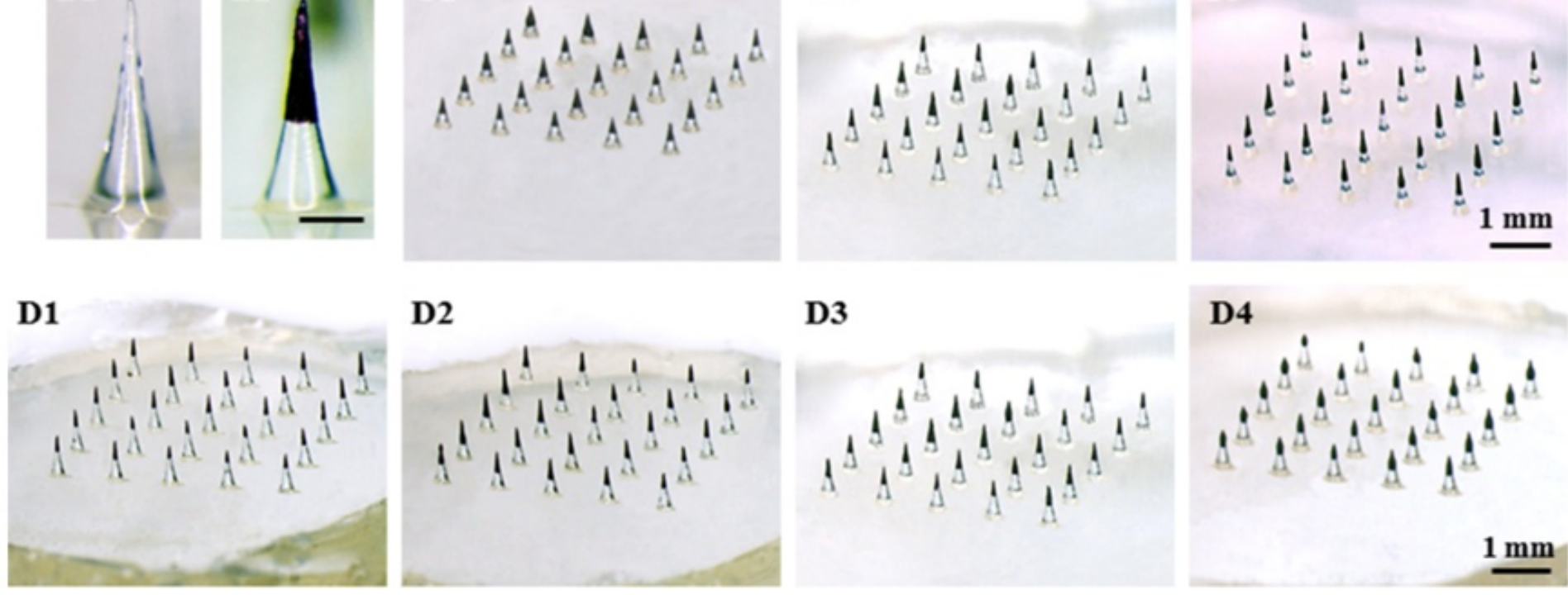

D2

D3
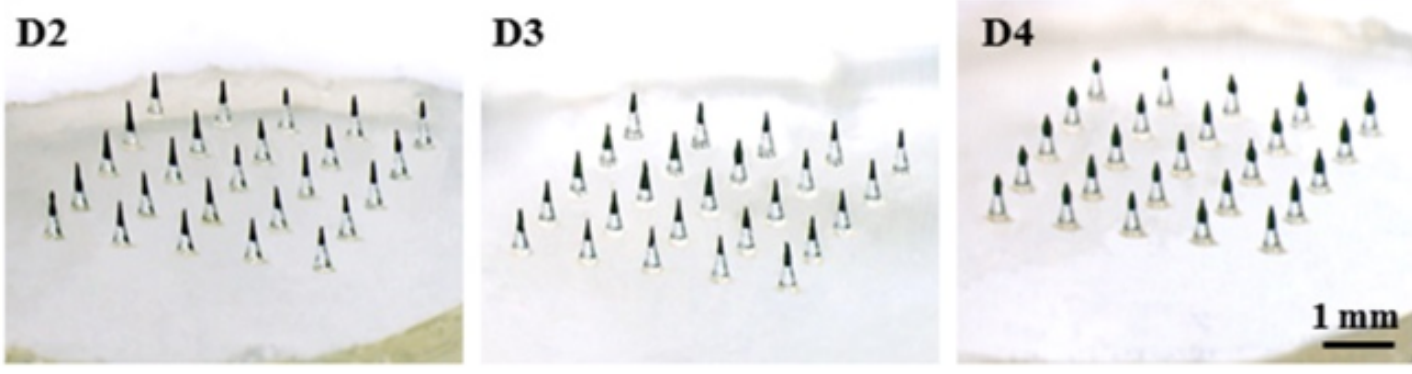

\section{Figure 1}

Fabrication of coated MNs with high drug loadings. (A) Schematic diagram of process to fabricate coated MNs. The coated MNs were fabricated by (I) dipping and (II) dring. (B1) and (B2) are partial enlarged images of solid $\mathrm{MN}$ and coated $\mathrm{MN}$, respectively. (C1-C3) Coated MNs with the coating formulation $\otimes$ and height of 550,650 and $750 \mu \mathrm{m}$. (D1-D4) Coated MNs with the coating formulation $\mathbb{\nabla} \nabla$ and height of $550 \mu \mathrm{m}$. The scale bar in Figure 1B2 $=200 \mu \mathrm{m}$. 

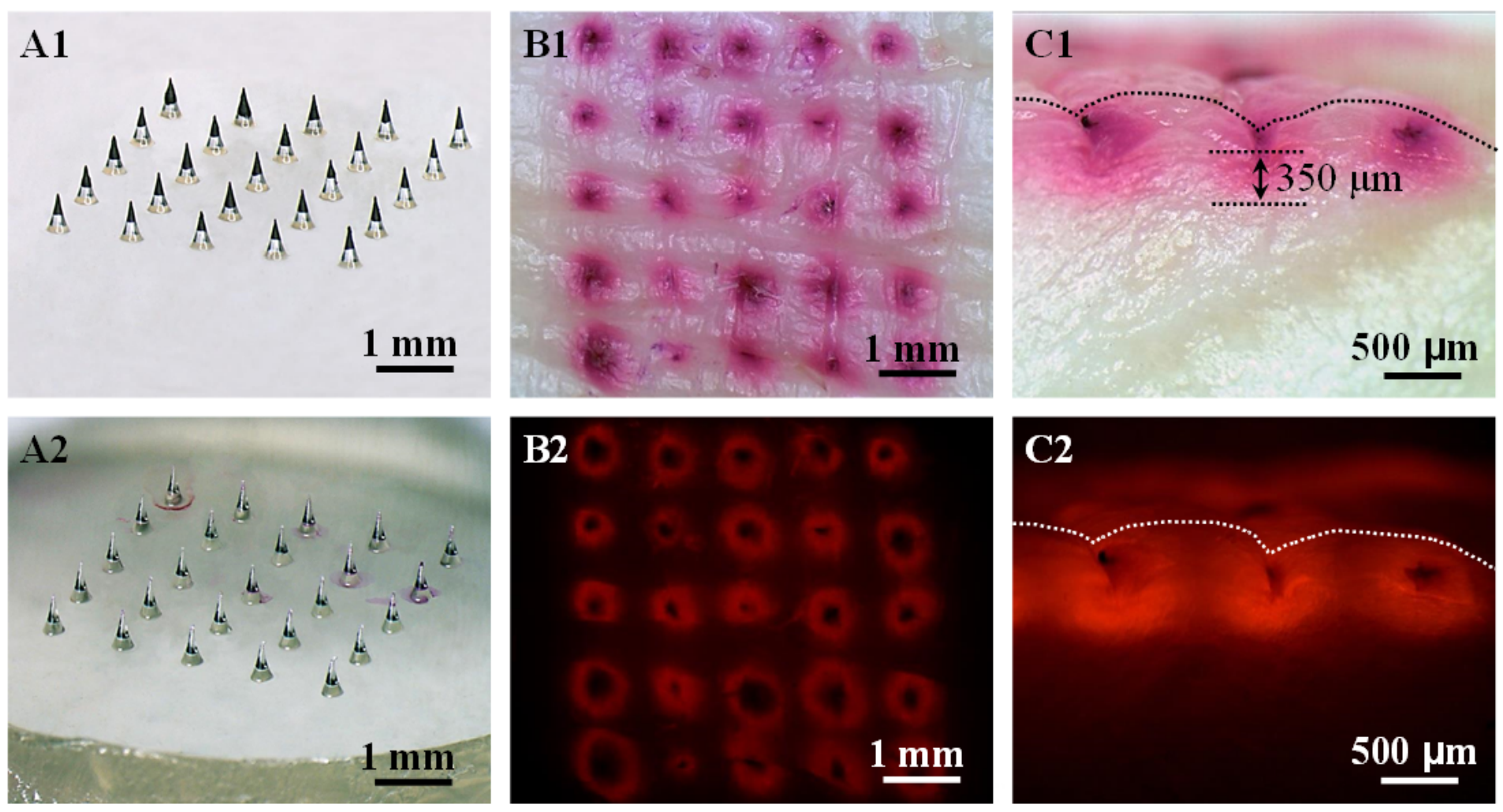

\section{Figure 2}

In vitro insertion capability of coated polymer MNs into porcine cadaver skin. (A1) The coated MN patch before insertion. (A2) The coated MN patch after insertion. (B1) The bright field image of porcine skin after the coated MN patch insertion. (B2) The fluorescent image of porcine skin after the coated MN patch insertion. (C1) The side view of porcine skin imaged by bright field. (C2) The side view of porcine skin imaged by fluorescent field. 
A

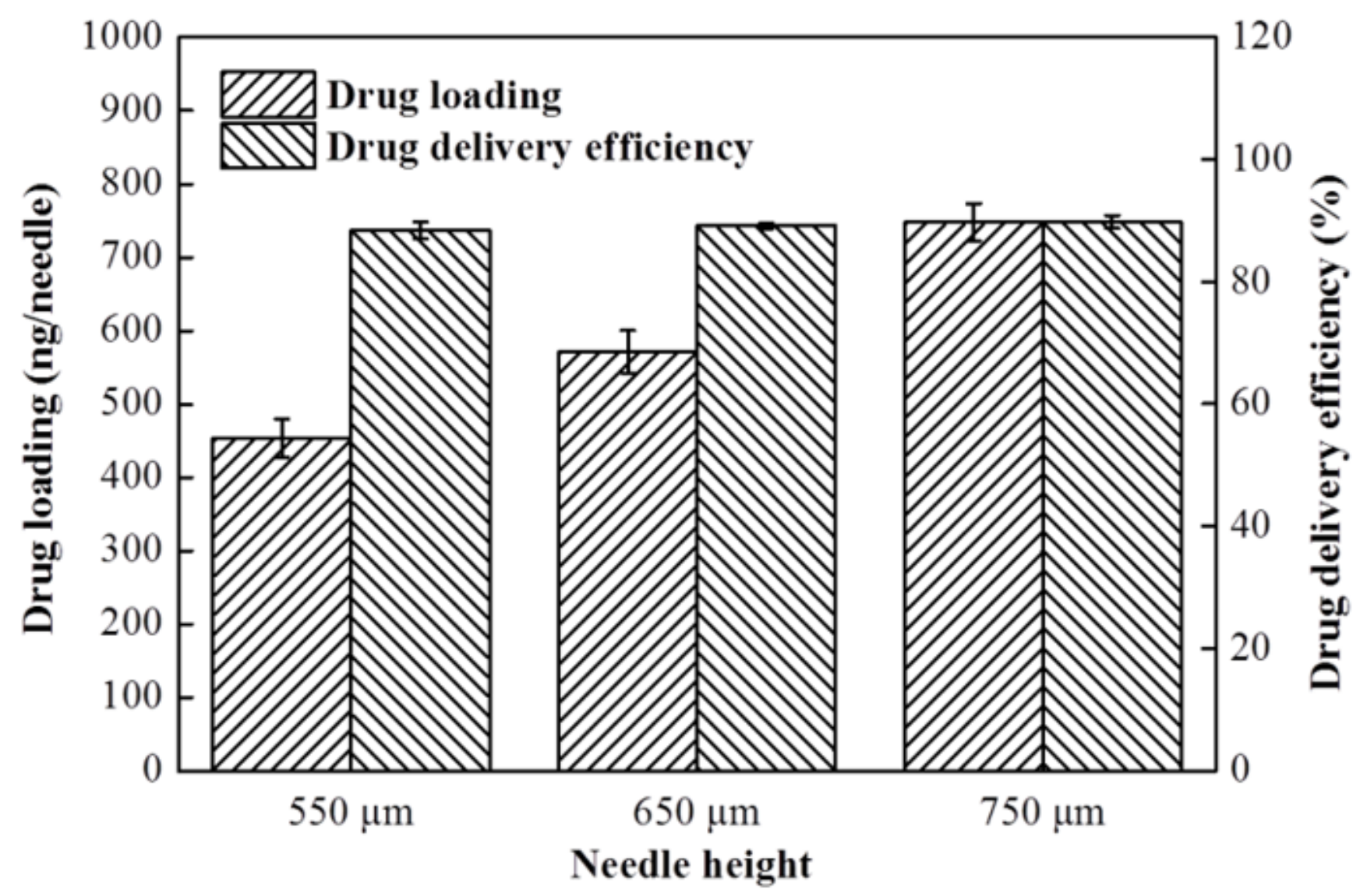

B

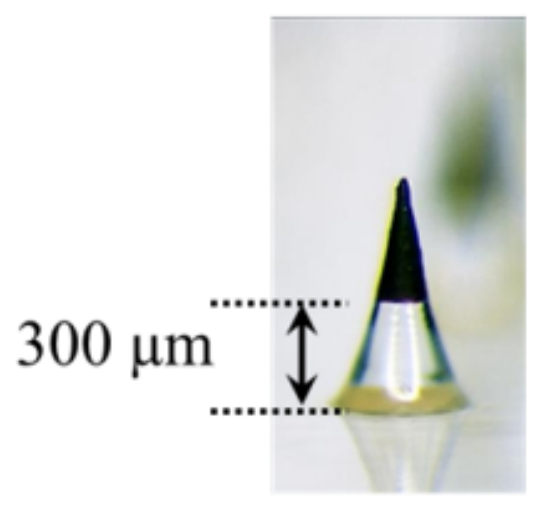

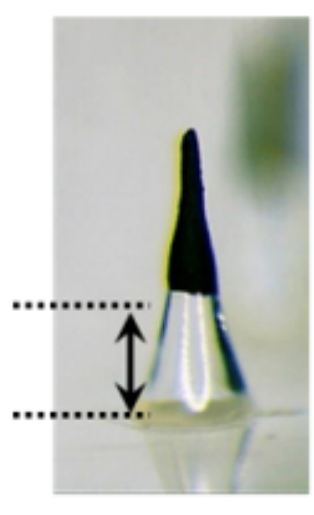

$650 \mu \mathrm{m}$

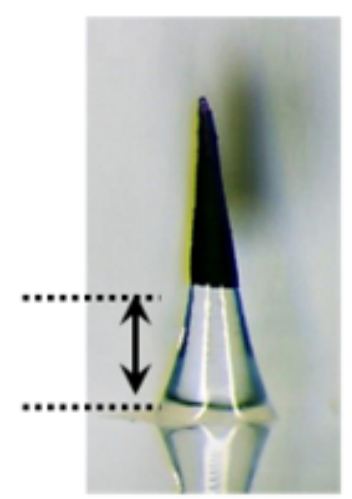

$750 \mu \mathrm{m}$

Figure 3

(A) Drug loading and drug delivery efficiency of coated polymer MNs. (B) Coated MNs with different heights and coating formulation $\otimes$. 
A

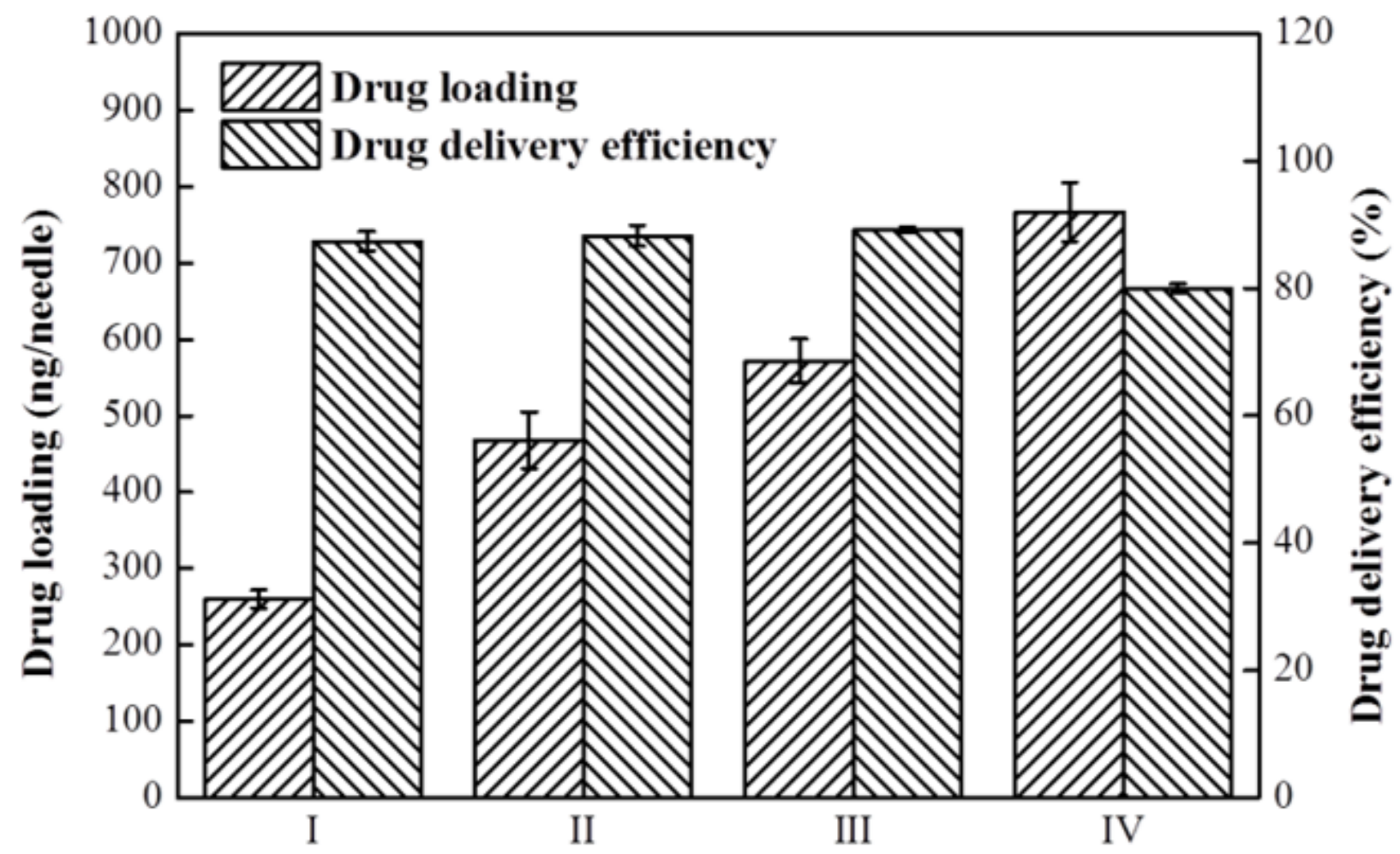

Formulation ID
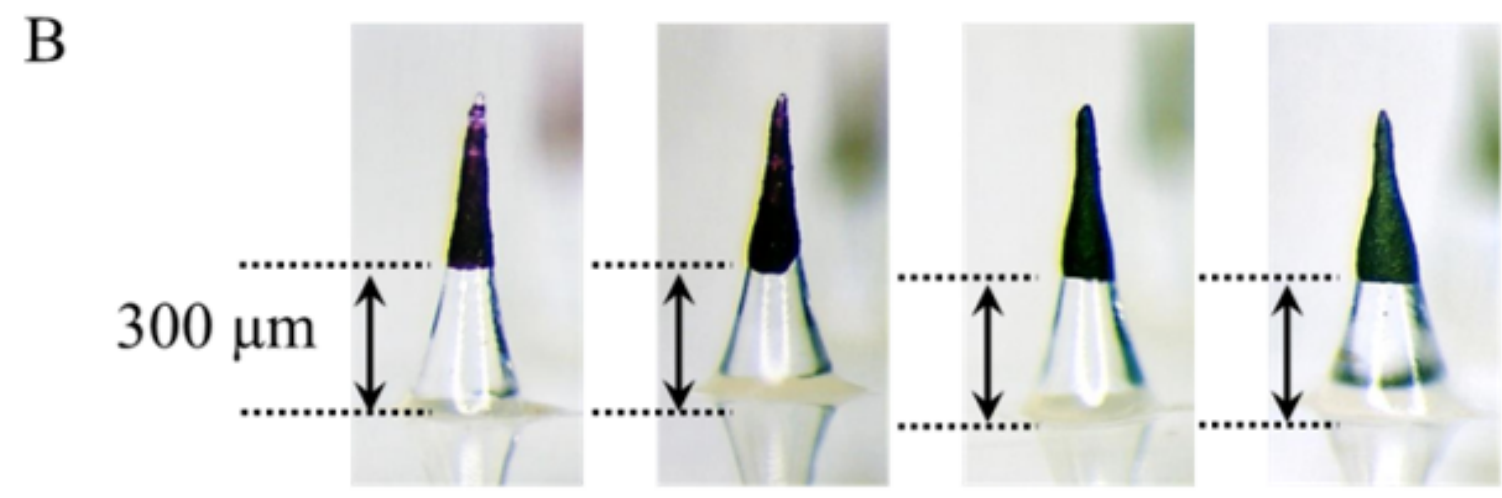

Formulation ID

I

II

III

IV

Figure 4

(A) Drug loading and drug delivery efficiency of coated polymer MNs. (B) Coated MNs with the height of

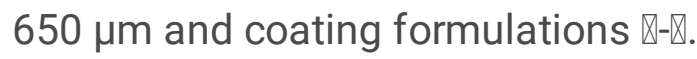



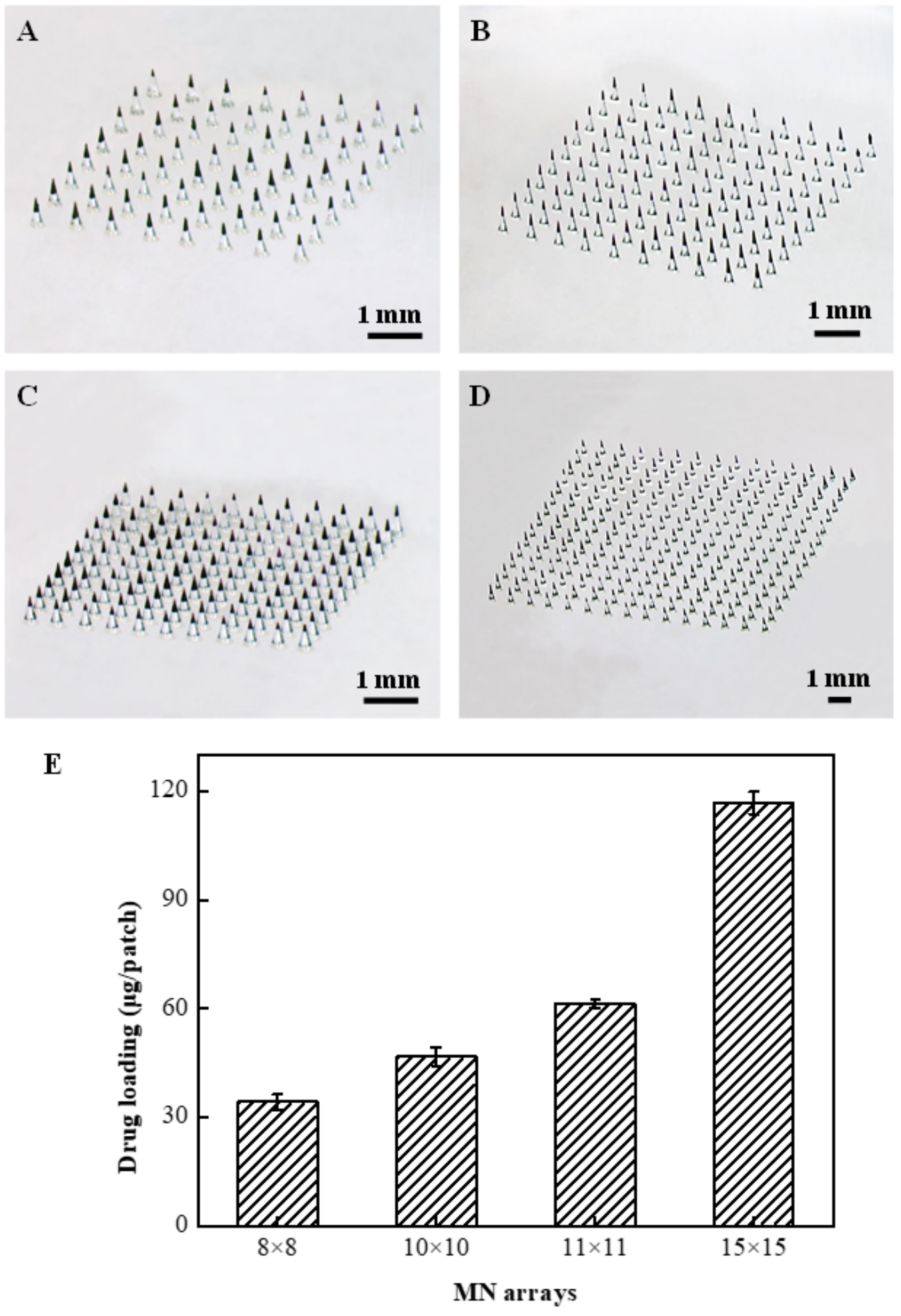

Figure 5

Large scale arrays of $650 \mu \mathrm{m}$-tall coated MNs and the drug loadings. Coated MNs with arrays of (A) $8 \times 8$, (B) $10 \times 10$, (C) $11 \times 11$ and (D) $15 \times 15$. (E) The drug loadings of different MN arrays. 

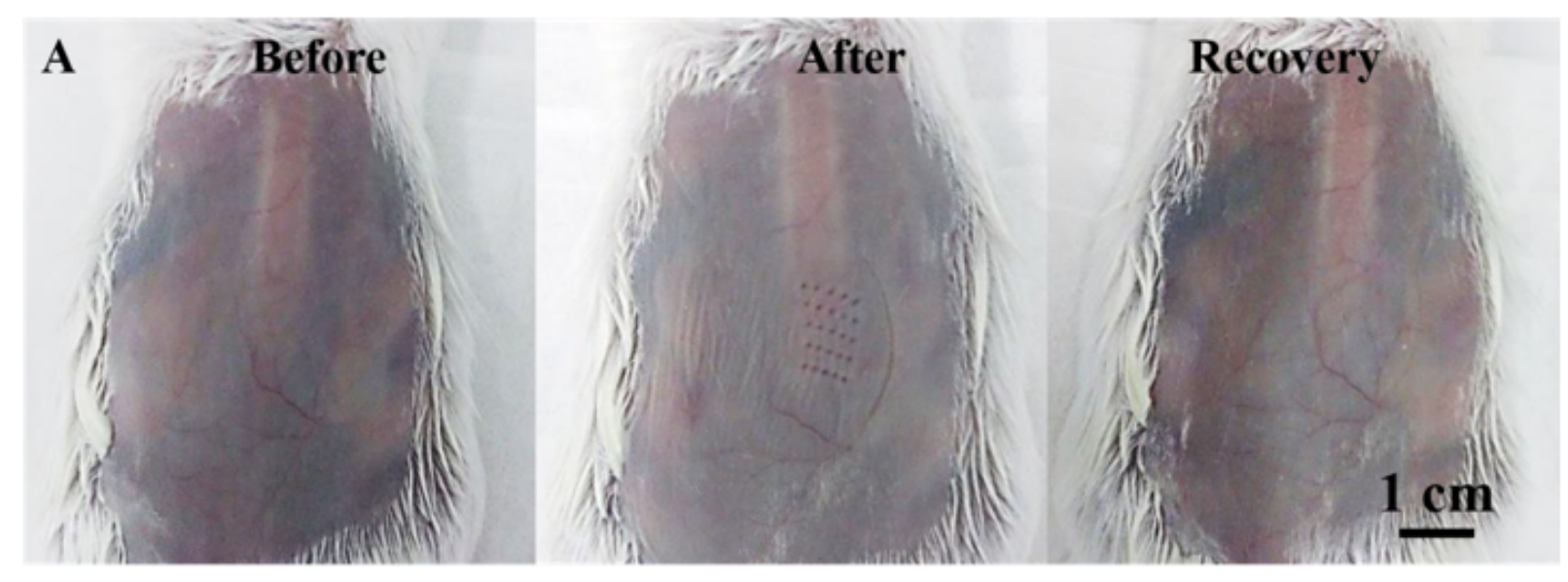

B

Before

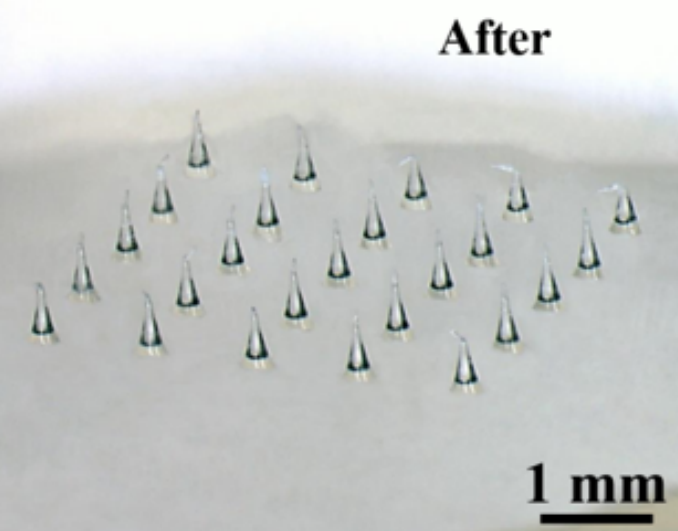

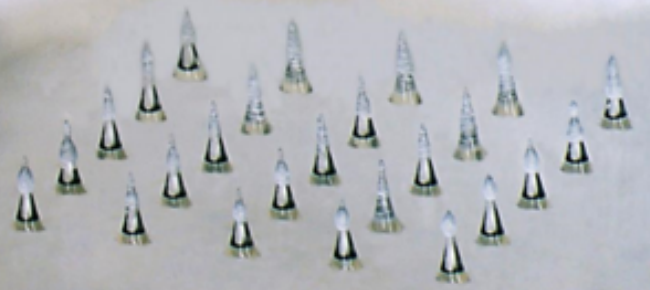

mm

C

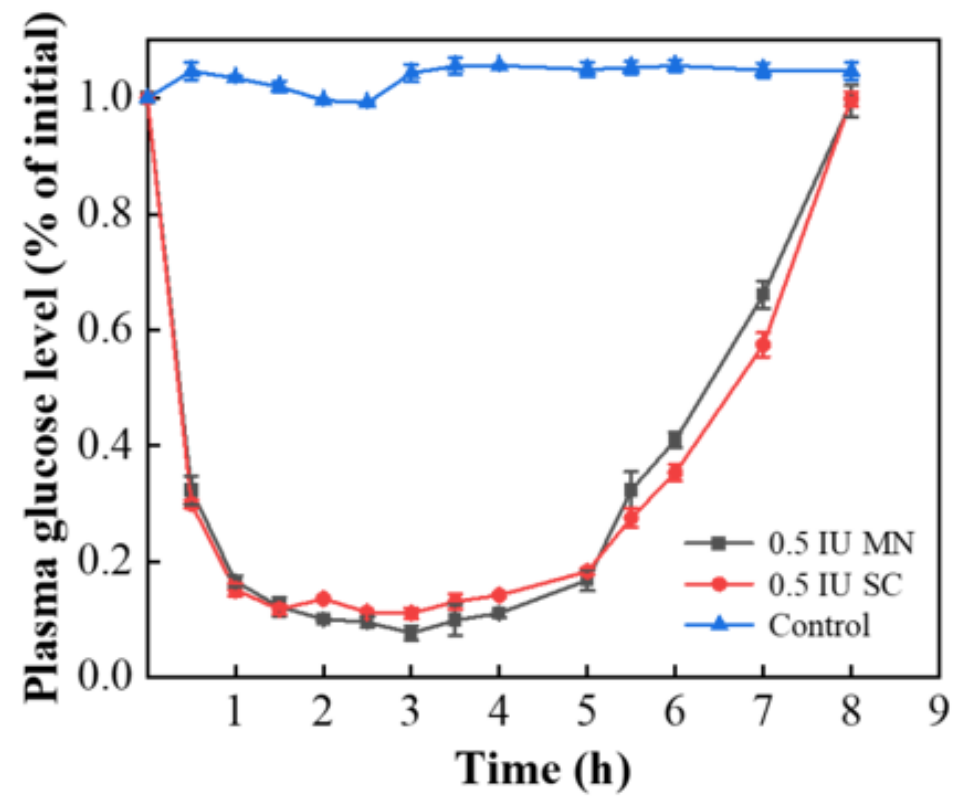

Figure 6

(A) The back skin of mouse during the MN insertion. (B) Insulin-coated MNs before and after insertion.

(C) Blood glucose level after a subcutaneous injection and an administration of insulin-coated MN array. 